\section{Several Environmental Pollutants Have Binding Affinities for Both Androgen Receptor and Estrogen Receptor $\boldsymbol{\alpha}$}

\author{
Kanako Satoh,* Fumiko Nagai, \\ and Naoto Aoki
}

Department of Toxicology, The Tokyo Metropolitan Research Laboratory of Public Health, 24-1, Hyakunincho 3-chome, Shinjuku-ku, Tokyo 169-0073, Japan

(Received May 8, 2001; Accepted July 4, 2001)

We determined the binding affinities of some chemicals suspected of having endocrine-disrupting effects for androgen and/or estrogen receptors (ADR and $\mathrm{ER} \alpha$ ) by a non-radioisotope (RI) receptor binding assay. Tributyltin had the highest binding affinity for ADR with an $\mathrm{IC}_{50}$ of $7.6 \times 10^{-6} \mathrm{M}$, but no affinity for $\operatorname{ER} \alpha$. Bisphenol $A$ and 4-nonylphenol strongly bound to both ADR $\left(\mathrm{IC}_{50}\right.$ values of $7.9 \times 10^{-6}$ and $1.3 \times 10^{-5} \mathrm{M}$, respectively) and $\mathrm{ER} \alpha\left(\mathrm{IC}_{50}\right.$ values of $7.8 \times 10^{-6}$ and $7.2 \times 10^{-7} \mathrm{M}$, respectively). Octachlorostyrene had affinity for both receptors $\left(\mathrm{IC}_{50}\right.$ for $\mathrm{ADR}, 2.7 \times \mathbf{1 0}^{-5} \mathrm{M}$; and for $\left.\mathbf{E R} \alpha, 7.0 \times 10^{-5} \mathrm{M}\right)$. Although 4-octylphenol had a low affinity for ADR, it had a high affinity for $\mathrm{ER} \alpha \quad\left(\mathrm{IC}_{50}\right.$ of $\left.9.8 \times 10^{-6} \mathrm{M}\right)$. Di- $n$-butyl phthalate, dicyclohexyl phthalate, and di(2-ethylhexyl) phthalate had low affinities for both ADR and $\operatorname{ER} \alpha$. The affinity of benzophenone was low for both receptors and $n$ butylbenzene had no affinity for either. Styrene trimers such as 1a-phenyl-4a-( $1^{\prime}$-phenylethyl)tetralin (ST-2), 1a-phenyl-4e-(1'-phenylethyl)tetralin (ST-3), 1e-phenyl-4a-(1'-phenylethyl)tetralin (ST-4), and 1ephenyl-4e-(1'-phenylethyl)tetralin (ST-5) had relatively high affinities, with $\mathrm{IC}_{50}$ values of 1.2-3.1 $\times 10^{-5} \mathrm{M}$. Styrene dimers showed lower affinities for ADR than the trimers. Some styrene oligomers have been previously reported to have binding affinities for $\mathrm{ER} \alpha$. These findings suggest that some chemicals possess binding affinities for ADR and $\operatorname{ER} \alpha$. It is necessary to examine the effects of substances on various hormone receptors to elucidate their endocrine-disrupting activities.

\footnotetext{
*To whom correspondence should be addressed: Department of Toxicology, The Tokyo Metropolitan Research Laboratory of Public Health, 24-1, Hyakunincho 3-chome, Shinjuku-ku, Tokyo 169-0073, Japan. Tel.: +81-3-3363-3231; Fax: +81-3-33684060; E-mail: sato@tokyo-eiken.go.jp
}

Key words — endocrine disrupter, androgen receptor, estrogen receptor, tributyltin, styrene oligomer

\section{INTRODUCTION}

A variety of synthetic chemicals has been released into the environment, some in large quantities, during the past several decades. There is increasing scientific evidence that many substances with different chemical structures can interfere with the normal hormonally regulated biological processes to adversely affect development and/or reproductive function in wildlife, experimental animals, and humans. ${ }^{1-3)}$ These environmental contaminants are able to alter the normal functioning of the endocrine and reproductive systems by mimicking or inhibiting endogenous hormone actions, or modulating the synthesis of hormones. ${ }^{4)}$ These types of chemicals have been given the term "environmental endocrine disrupters" or "hormonally active agents." Endocrine disrupters are composed of numerous types of chemicals used in a wide variety of herbicides, fungicides, insecticides, detergents, materials of plastics, and many others. To clarify the endocrine-disrupting effect in chemical substances, versatile international collaborations have been performed. The Ministry of the Environment, Government of Japan, released a document titled "Strategic Programs on Environmental Endocrine Disrupters SPEED '98" in 1998 and a second edition in 2000, and 67 substances were listed as chemicals suspected of causing endocrine disruption in the document. Furthermore, tributyltin, 4-octylphenol, nonylphenol, di- $n$-butyl phthalate, dicyclohexyl phthalate, di(2-etylhexyl) phthalate, octachlorostyrene, benzophenone, and $n$-butylbenzene have been selected as substances on which priority risk assessments will be conducted as part of a three year program starting in 2000 under the government's Millennium Project.

A series of in vitro assays have been developed for the detection of disruptive activity as a first screening. One is an estrogen receptor (ER) competitive binding assay that measures the binding affinity of chemicals for receptors. Recently, it has become possible to perform the assays without using radioisotope (RI)-labeled compounds. We have applied this assay to determine whether the chemicals had estrogenic activity, and confirmed the binding affinities of some parabens for human ERs $\alpha$ and 
$\beta(\mathrm{ER} \alpha$ and $\mathrm{ER} \beta) .{ }^{5)}$ Furthermore, a non-RI competitive binding assay for androgen receptor (ADR) has been established as a screening for hormonally active chemicals. We evaluated the binding affinities for both ADR and ER to determine whether the nine substances listed above have androgenic and estrogenic effects. It was determined that the styrene oligomers (1,3-diphenyl propane, SD-1; 2,4-diphenyl1-butene, SD-2; cis-1,2-diphenylcyclobutane, SD3; trans-1,2-diphenylcyclobutane, SD-4; 2,4,6triphenyl-1-hexene, ST-1; 1a-phenyl-4a-(1'phenylethyl)tetralin, ST-2; 1a-phenyl-4e-(1'phenylethyl)tetralin, ST-3; 1e-phenyl-4a-(1'phenylethyl)tetralin, ST-4; 1e-phenyl-4e-(1'phenylethyl)tetralin, ST-5; and 1,3,5-triphenylcyclohexane (ST-6) had estrogenic effects. ${ }^{6}$ In this study, the androgenic binding affinities of the styrene oligomers were examined.

\section{MATERIALS AND METHODS}

Reagent — Chemicals were of the highest grade commercially available or for the environmental analysis. The styrene dimers SD-1 (>99.5\% pure), SD-2 (> 99.0\% pure), SD-3 (100\% pure), and SD-4 (>98.5\% pure), the styrene trimers ST-1 (>97.8\% pure), ST-2 (>99.7\% pure), ST-3 (>99.0\% pure), ST-4 (> 99.6\% pure), ST-5 (> 99.8\% pure), and ST6 (>99.9\% pure), tri- $n$-butyltin (IV) acetate (tri- $n$ butyltin, $>95 \%$ pure), 4-nonylphenol (> 98\% pure), octachlorostyrene (>99\% pure), $n$-butylbenzene (>99\% pure), and benzophenone (>99\% pure) were purchased from Wako Pure Chemical Industries, Ltd. (Osaka, Japan). 4-Octylphenol (> 98\% pure), di- $n$ butyl phthalate ( $>98 \%$ pure), dicyclohexyl phthalate $(>99.0 \%$ pure), di(2-ethylhexyl) phthalate (>98.0\% pure), bisphenol A ( $>99.0 \%$ pure), and diethylstilbestrol (DES, $>98.0 \%$ pure) were purchased from Tokyo Chemical Industries Co., Ltd. (Tokyo, Japan). These chemicals were prepared as solutions in dimethyl sulfoxide.

\section{ADR and ER Competitive Binding Assay}

The ADR competitive binding assay was determined using a Ligand Screening System-Androgen Receptor kit (Toyobo Co., Ltd, Osaka, Japan). Solutions of human ADR, unlabeled testosterone, and chemicals were reacted at $4^{\circ} \mathrm{C}$ for $1 \mathrm{hr}$. The liberated testosterone was allowed to compete with anti-testosterone antibody and peroxidase-labeled testosterone at $4^{\circ} \mathrm{C}$ for $1 \mathrm{hr}$. Plates were washed using a wash solution, and then the substrate solution was added. The developed color was read at $450 \mathrm{~nm}$ on a microplatespectrophotometer.

The ER $\alpha$ competitive binding assay was determined using an Estrogen-R $(\alpha)$ Competitor Screening kit (Wako Pure Chemical Industries, Ltd., Osaka, Japan), essentially according to the method reported previously. ${ }^{5)}$ Solutions of fluorescence-labeled $17 \beta$ estradiol $\left(E_{2}\right)$ and chemicals were added to the wells of a plate coated with human $\operatorname{ER} \alpha$, and they were allowed to compete at room temperature for $2 \mathrm{hr}$. The plates were washed using the wash solution, and then the assay solution was added to each well. The fluorescence intensity was detected with a microplate-fluoresencephotometer (excitation at $485 \mathrm{~nm}$, emission at $535 \mathrm{~nm}$ ).

\section{RESULTS}

\section{Binding of Chemicals to ADR}

Various concentrations of each chemical were reacted with human ADR with testosterone, and the competition curves are shown in Fig. 1a-1d. The $\mathrm{IC}_{50}$ values (concentration of chemical required to reduce the specific testosterone binding by 50\%) were obtained from the curves, and the relative binding affinities for ADR (RBA-A) were indicated as the ratio of $\mathrm{IC}_{50}$ of mibolerone, a synthetic anobolic testosterone, to that of each chemical (Tables 1 and 2)

Tributyltin: Tri- $n$-butyltin bound the most tightly to ADR among tested chemicals. A slight inhibition of the specific binding appeared at $1.9 \times 10^{-6} \mathrm{M}$. The inhibition was concentration dependent, and complete inhibition appeared at $1.9 \times 10^{-5} \mathrm{M}$. The $\mathrm{IC}_{50}$ and RBA-A for ADR were $7.6 \times 10^{-6} \mathrm{M}$, and 0.224 , respectively.

Phenolic compounds: Bisphenol A and 4nonylphenol had high binding affinity for ADR. The $\mathrm{IC}_{50}$ of the former was $7.9 \times 10^{-6} \mathrm{M}$ and that of the latter was $1.3 \times 10^{-5} \mathrm{M}$. The RBA-As were 0.215 and 0.131 , respectively. 4-Octylphenol did not completely inhibit the specific binding, and only $34 \%$ inhibition was obtained at $1.9 \times 10^{-4} \mathrm{M}$.

Phthalates: Di- $n$-butyl phthalate, dicyclohexyl phthalate or di(2-ethylhexyl) phthalate had the partial inhibitory effects on specific binding to ADR. About $45 \%$ inhibition of specific binding occurred with each chemical at $1.9 \times 10^{-4} \mathrm{M}$.

Styrene oligomers: Among the styrene dimers, SD-2 completely inhibited specific binding to ADR. The $\mathrm{IC}_{50}$ and RBA-A were $4.3 \times 10^{-5} \mathrm{M}$ and 0.040 , respectively. SD-3 and SD-4 did not completely in- 

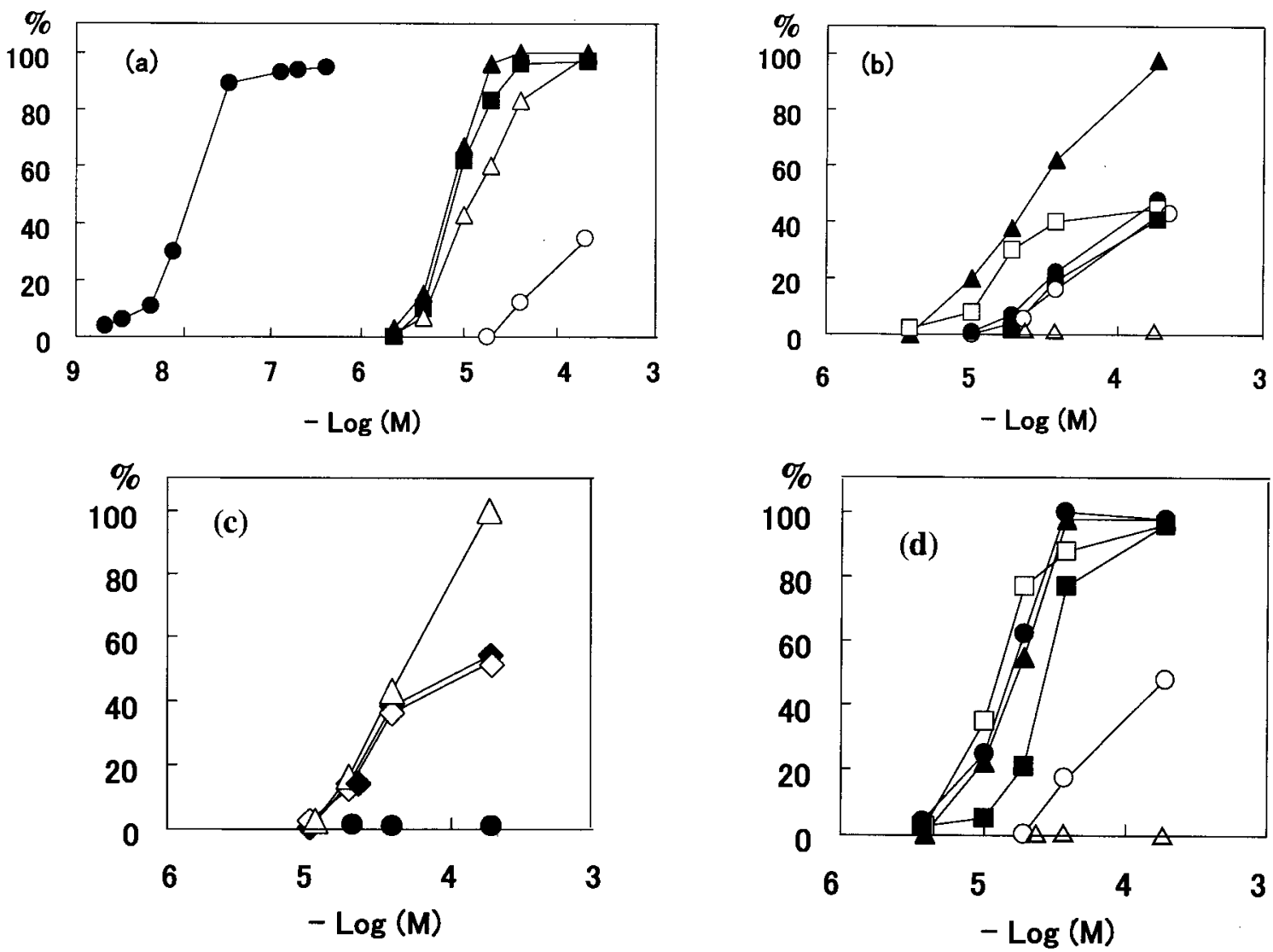

Fig. 1. Competition by Chemicals for Testosterone Binding to Androgen Receptor

Ligand binding experiments were carried out using a Ligand Screening System-Androgen Receptor kit (Toyobo, Japan). The SD was less than 2.6\% $(n=5)$. Ordinates: $\%$ of inhibition $=\mathrm{A}-\mathrm{B} / \mathrm{A}$ (A and B were the fluorescence intensities in the absence and presence of competitor, respectively. (a) mibolerone; $\mathbf{\square}$, bisphenol A; $\triangle$, 4-nonylphenol; $\bigcirc$, 4-octylphenol; $\mathbf{\Lambda}$, tri- $n$-butyltin(IV) acetate. (b) $\bigcirc$, benzophenone; $\boldsymbol{\Lambda}$, octachlorostyrene; $\boldsymbol{\bullet}$, di- $n$ butyl phthalate; $\square$, dicyclohexyl phthalate; $\boldsymbol{\square}$, di(2-ethylhexyl) phthalate; $\triangle, n$-butylbenzene. (c) $\bullet$, SD-1; $\triangle$, SD-2; $\diamond$, SD-3; $\diamond$, SD-4. (d) $\bigcirc$, ST-1; $\square$, ST-2;, ST-3; $\mathbf{\square}$, ST-4; $\boldsymbol{\Delta}$, ST-5; $\triangle$, ST-6.

Table 1. Binding Affinities of Chemicals for ADR and ER $\alpha$

\begin{tabular}{|c|c|c|c|c|}
\hline \multirow[b]{2}{*}{ Compound } & \multicolumn{2}{|c|}{ ADR } & \multicolumn{2}{|c|}{$\mathrm{ER} \alpha$} \\
\hline & $\mathrm{IC}_{50}(\mathrm{M})$ & $\mathrm{RBA} \mathrm{A}^{a)}$ & $\mathrm{IC}_{50}(\mathrm{M})$ & RBA-E $^{b)}$ \\
\hline Mibolerone & $1.7 \times 10^{-8}$ & 100 & - & - \\
\hline DES & - & - & $1.6 \times 10^{-8}$ & 100 \\
\hline Tri- $n$-butyltin & $7.6 \times 10^{-6}$ & 0.224 & $\mathrm{NE}^{c)}$ & - \\
\hline 4-Octylphenol & $>1.9 \times 10^{-4}$ & $<0.009$ & $9.8 \times 10^{-6}$ & 0.163 \\
\hline 4-Nonylphenol & $1.3 \times 10^{-5}$ & 0.131 & $7.2 \times 10^{-7}$ & 2.222 \\
\hline Bisphenol A & $7.9 \times 10^{-6}$ & 0.215 & $7.8 \times 10^{-6}$ & 0.205 \\
\hline Di- $n$-butyl phthalate & $>1.9 \times 10^{-4}$ & $<0.009$ & $1.9 \times 10^{-4}$ & 0.008 \\
\hline Dicyclohexyl phthalate & $>1.9 \times 10^{-4}$ & $<0.009$ & $5.8 \times 10^{-5}$ & 0.028 \\
\hline Di(2-ethylhexyl) phthalate & $>1.9 \times 10^{-4}$ & $<0.009$ & $1.5 \times 10^{-4}$ & 0.011 \\
\hline Octachlorostyrene & $2.7 \times 10^{-5}$ & 0.063 & $7.0 \times 10^{-5}$ & 0.023 \\
\hline Benzophenone & $>1.9 \times 10^{-4}$ & $<0.009$ & $>1.9 \times 10^{-4}$ & $<0.008$ \\
\hline$n$-Butylbenzene & $\mathrm{NE}^{c)}$ & - & $\mathrm{NE}^{c)}$ & - \\
\hline
\end{tabular}

a) RBA-A and $b$ ) RBA-E were calculated as a ratio of the $\mathrm{IC}_{50}$ value of mibolerone (synthesis of anabolic testosterone) to that of the chemical, and a ratio of the $\mathrm{IC}_{50}$ value of diethylstilbestrol (DES) to that of the chemical, respectively. $c$ ) NE; no effect at $1.9 \times 10^{-4} \mathrm{M}$. 
Table 2. Binding Affinities of Styrene Oligomers for ADR

\begin{tabular}{lcc}
\hline \hline Compound & $\mathrm{IC}_{50}(\mathrm{M})$ & $\mathrm{RBA}^{a} \mathrm{~A}^{a}$ \\
\hline Mibolerone & $1.7 \times 10^{-8}$ & 100 \\
& & - \\
1,3-diphenyl propane (SD-1) & $\mathrm{NE}^{b)}$ & 0.040 \\
2,4-diphenyl-1-betene (SD-2) & $4.3 \times 10^{-5}$ & 0.012 \\
cis-1,2-diphenylcyclobutane (SD-3) & $1.4 \times 10^{-4}$ & 0.013 \\
trans-1,2-diphenylcyclobutane (SD-4) & $1.5 \times 10^{-4}$ & $<0.009$ \\
2,4,6-triphenyl-1-hexene (ST-1) & $>1.9 \times 10^{-4}$ & 0.142 \\
1a-phenyl-4a-(1'-phenylethyl)tetralin (ST-2) & $1.2 \times 10^{-5}$ & 0.106 \\
1a-phenyl-4e-(1'-phenylethyl)tetralin (ST-3) & $1.6 \times 10^{-5}$ & 0.055 \\
1e-phenyl-4a-(1'-phenylethyl)tetralin (ST-4) & $3.1 \times 10^{-5}$ & 0.094 \\
1e-phenyl-4e-(1'-phenylethyl)tetralin (ST-5) & $1.8 \times 10^{-5}$ & - \\
1,3,5-triphenylcyclohexane (ST-6) & $\mathrm{NE}^{b)}$ & - \\
\hline
\end{tabular}

a) RBA-A was calculated as a ratio of the $\mathrm{IC}_{50}$ value of mibolerone to that of the styrene oligomer. $b$ ) NE; no effect at $1.9 \times 10^{-4} \mathrm{M}$.
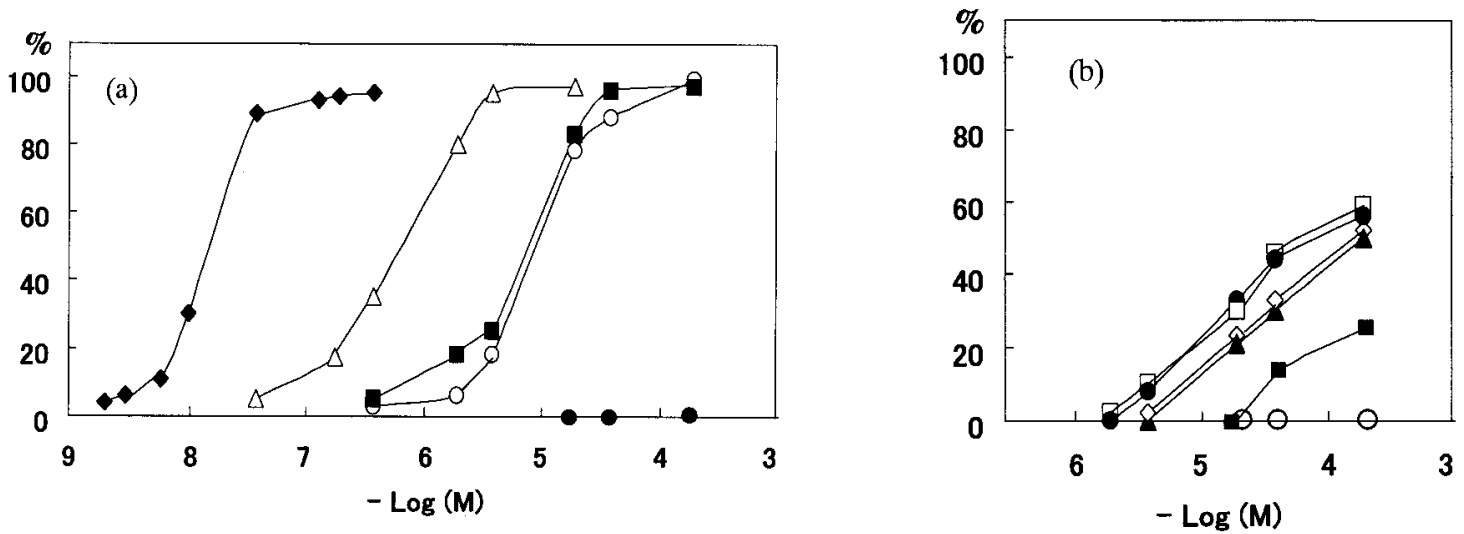

Fig. 2. Competition by Chemicals for Estradiol Binding to Estrogen Receptor $\alpha$

Ligand binding experiments were carried out using an Estrogen-R $(\alpha)$ Competitor Screening kit (Wako, Japan). The SD was less than 2.5\% $(n=5)$. Ordinates: \% of inhibition = A - B/A (A and B were optical density in the absence and presence of competior, respectively). (a) $\downarrow$, diethylstilbestrol; $\triangle$, 4-nonylphenol; $\boldsymbol{\square}$, bisphenol A; $\bigcirc$, 4-octylphenol; $\bullet$, tri- $n$-butyltin (IV) acetate. (b) $\square$, dicyclohexyl phthalate; $\bullet$, octachlorostyrene; $\diamond$, di(2-ethylhexyl) phthalate; $\boldsymbol{\Lambda}$, di- $n$-butyl phthalate; $\mathbf{\square}$, benzophenone; $\bigcirc, n$-butylbenzene.

hibit binding, and about $53 \%$ inhibition was obtained with each chemical at $1.9 \times 10^{-4} \mathrm{M}$. SD-1 did not bind to ADR.

The binding affinities of the styrene trimers for ADR were relatively higher than those of the dimers. The $\mathrm{IC}_{50}$ values of ST-2, ST-3, ST-4, and ST-5 were $1.2 \times 10^{-5}, 1.6 \times 10^{-5}, 3.1 \times 10^{-5}$, and $1.8 \times 10^{-5} \mathrm{M}$, respectively. The RBA-As were $0.142,0.106,0.055$, and 0.094 , respectively. The binding affinity of ST1 was lower than that of the other trimers, and $48 \%$ inhibition appeared at $1.9 \times 10^{-4} \mathrm{M}$. ST- 6 did not bind to ADR.

Other chemicals: The inhibition of specific binding to $\mathrm{ADR}$ by octachlorostyrene was concentration dependent. The $\mathrm{IC}_{50}$ and RBA-A were $2.7 \times 10^{-5} \mathrm{M}$ and 0.063 , respectively. Benzophenone at
$1.9 \times 10^{-4} \mathrm{M}$ inhibited the binding to ADR by $48 \%$. $n$-Butylbenzene did not bind to ADR.

\section{Binding of chemicals to $\mathrm{ER} \alpha$}

Different concentrations of each chemical were reacted with human $\mathrm{ER} \alpha$ with $\mathrm{E}_{2}$, and the competition curves were obtained (Fig. 2a and $2 \mathrm{~b}$ ). The $\mathrm{IC}_{50}$ values were obtained from the curves, and the relative binding affinities for $\mathrm{ER} \alpha$ (RBA-E) were indicated as the ratio of the DES $\mathrm{IC}_{50}$ to that of each chemical (Table 1).

Phenolic compounds: These chemicals had relatively high affinities for ER $\alpha$. The affinity of 4nonylphenol was the highest among the tested chemicals, and the $\mathrm{IC}_{50}$ value and RBA-E were $7.2 \times 10^{-7} \mathrm{M}$ and 2.222 , respectively. The $\mathrm{IC}_{50}$ and 
RBA-E of bisphenol A were $7.8 \times 10^{-6} \mathrm{M}$ and 0.205 , respectively. The two values for 4-octylphenol were $9.8 \times 10^{-6} \mathrm{M}$ and 0.163 , respectively.

Phthalates: The phthalates tested in this experiment did not completely inhibit specific binding to $\mathrm{ER} \alpha$. The $\mathrm{IC}_{50}$ value and RBA-E of di- $n$-butyl phthalate were $1.9 \times 10^{-4} \mathrm{M}$ and 0.008 , respectively. The values of dicyclohexyl phthalate were $5.8 \times 10^{-5} \mathrm{M}$ and 0.028 , respectively, and those of $\operatorname{di}\left(2\right.$-ethylhexyl) phthalate were $1.5 \times 10^{-4} \mathrm{M}$ and 0.011 , respectively.

Other chemicals: Octachlorostyrene inhibited the specific binding to $\mathrm{ER} \alpha$ in a concentration-dependent manner. The $\mathrm{IC}_{50}$ value and $\mathrm{RBA}-\mathrm{E}$ were $7.0 \times 10^{-5} \mathrm{M}$ and 0.023 , respectively. The inhibition by benzophenone at $1.9 \times 10^{-4} \mathrm{M}$ was only $25 \%$. The binding of tri- $n$-butyltin and $n$-butylbenzene to ER $\alpha$ was not detected.

\section{DISCUSSION}

Organotin compounds had been used worldwide for antifouling paint of ship hulls and for fishing nets since 1969, but they have not been approved for use from about 12 years ago in Japan. However, these substances still remain in marine organisms and sediments on the seabed. ${ }^{7)}$ These organotins have been reported to cause imposex in marine female gastropods. ${ }^{8,9)}$ It has been suggested that tributyltin brought about imposex in female marine gastropods mediated by an increasing androgen level caused by the inhibition of aromatase activity by tributyltin. ${ }^{10-12)}$ On the other hand, Shiraishi et al. ${ }^{13)}$ suggested that organotin compounds were estrogen antagonists. In this study, tri- $n$-butyltin bound to ADR although it had no affinity for $\mathrm{ER} \alpha$. The binding of tributyltin to ADR is thought to be a possible mechanism for the occurrence of the imposex. Tributyltin may be considered to work as an androgen agonist based on our results.

4-Octylphenol, 4-nonylphenol, and bisphenol A are industrial raw materials used in large quantities in a wide variety of surfactants and plastics and have been responsible for contaminating food and the environment worldwide. ${ }^{14,15)}$ There is accumulating evidence that these compounds influcence the actions of estrogen. ${ }^{1-3,16-19)}$ Moreover, bisphenol A has been reported to have anti-androgenic activity, and 4-nonylphenol was a weak androgen agonist in in vitro yeast-based assays. ${ }^{4)} \mathrm{We}$ found that bisphenol A and 4-nonylphenol had relatively high binding affinities for both ADR and ER $\alpha$. These compounds have estrogenic activity, and furthermore they might block or mimic the action of androgen through binding to an ADR.

Phthalate esters are produced in extremely large volumes and used as plasticizers in polymeric materials such as polyvinylchloride. ${ }^{20)}$ These substances such as di(2-ethylhexyl) phthalate, di- $n$-butyl phthalate, and dicyclohexyl phthalate are released into the environment and food samples (cheese, cream, butters, etc.) via volatilization and leaching from plasticware and other sources..$^{21)}$ There is some evidence of the estrogenic behavior of certain phthalates from in vitro ${ }^{22-25)}$ and in vivo ${ }^{26)}$ studies. Our experiment shows that the phthalates have binding affinities for both ADR and ER $\alpha$.

Octachlorostyrene, a by-product of organic chlorine compounds, is an environmental contaminant in the Great Lake regions of North America and the Norwegian coast in Europe, ${ }^{27,28)}$ and was found to be concentrated in the human plasma of aluminum foundry workers. ${ }^{29,30)}$ In vivo experiments have recognized histological and functional changes in the thyroid. ${ }^{28)}$ We found that octachlorostyrene had binding affinities for both ADR and ER $\alpha$. The results suggest that they have the mimicking or blocking effects on the actions of androgen and estrogen.

Benzophenone is widely used as a synthetic raw material for medical products, perfumes, cosmetics etc., and is a constituent of fruits such as the muscat grape and mango. Vaz et al. have indicated antagonist impediment by benzophenone to aromatase cytochrome $\mathrm{P} 450$ in vitro. ${ }^{31)}$ Benzophenone has binding affinities for both ADR and ER $\alpha$. Furthermore, $p$-hydroxybenzophenone, a metabolite of benzophenone, had proliferative activity in MCF7 cells. ${ }^{32)} \mathrm{We}$ consider it necessary to examine the binding affinity of the metabolites for hormone receptors.

$n$-Butylbenzene, a synthesis intermediate in the chemical reaction, induced cytochrome $\mathrm{P} 450$ isozymes in rat liver, and it inhibited testosterone hydroxylation activity. ${ }^{33)}$ As the substance did not bind to $\mathrm{ADR}$ and $\mathrm{ER} \alpha$ at high concentration $\left(1.9 \times 10^{-4} \mathrm{M}\right)$, it was considered to have no estrogenic or androgenic activities.

Styrene oligomers, especially styrene trimers, are contaminats in polystyrene ware used widely for food containers. ${ }^{34-36)}$ These styrene oligomers migrate from the polystyrene containers into the contents, such as instant food, when heated in a microwave oven or incubated at $20^{\circ} \mathrm{C}$ for $24 \mathrm{hr}^{34,35,37)}$ The styrene trimers (ST-1, ST-2, ST-3, ST-4, and ST-5) 
were shown to be estrogenic according to the assay of MCF-7 proliferative activity and the competitive binding assay to ER $\alpha{ }^{6}{ }^{6}$ Presently, styrene trimers (ST-2, ST-3, ST-5) also have relatively high binding affinities for ADR. We must investigate further the hormone-like activities of the styrene trimers.

This study demonstrates that hormonally active agents in the environment have multifarious activities, which may make it difficult to interpret their mechanisms of action in vivo. The kits determining the binding assay for ADR and ER $\alpha$ are useful for the prescreening of many chemicals.

\section{REFERENCES}

1) Kuiper, G. G. J. M., Lemmen, J. G., Carlsson, B., Corton, J. C., Safe, S. H., Saag, P. T., Burg, B. and Gustafsson, J. (1998) Interaction of estrogenic chemicals and phytoestrogens with estrogen receptor B. Endocrinology, 139, 4252-4263.

2) Hiroi, H., Tsutsumi, O., Momoeda, M., Takai, Y., Osuga, Y. and Taketani, Y. (1999) Differential interactions of bisphenol A and $17 \beta$-estrodiol with estrogen receptor $\alpha(\mathrm{ER} \alpha)$ and $\mathrm{ER} \beta$. Endcr. J., 46, 773-778.

3) Tabira, Y., Nakai, M., Asai, D., Yakabe, Y., Tahara, Y., Shinmyozu, T., Noguchi, M., Takatsuki, M. and Shimohigashi, Y. (1999) Structural requirements of para-alkylphenols to bind to estrogen receptor. Eur. J. Biochem., 262, 240-245.

4) Sonnennschein, C. and Soto, A. M. (1998) An update review of environmental estrogen and androgen mimics and antagonists. J. Steroid Biochem. Mol. Biol., 65, 143-150.

5) Satoh, K., Nagai, F., Aoki, N. and Nishijima, M. (2000) Competitive binding of some alkyl $p$ hydroxybenzoates to human estrogen receptor $\alpha$ and 3. J. Pharm. Soc. Jpn., 120, 1429-1433.

6) Oyama, K., Nagai, F. and Tsuchiya, Y. (2001) Certain styrene oligomers have proliferative activity on MCF-7 human brest tumor cells and binding affinity for human estrogen receptor $(\alpha)$. Environ. Health Perspect., 109, 699-703.

7) Ministry of the Environment, Government of Japan, Ed. (2000) Chemical Substances and the Environment.

8) Horiguchi, T., Shiraishi, H., Shimuzu, M., Yamazaki, S. and Morita, M. (1995) Imposex in Japanese gastropods (Neogastropoda and Mesogastropoda): Effects of tributyltin and triphenyltin from antifouling paints. Mar. Pollut. Bull., 31, 402-405.

9) Horiguchi, T., Shiraishi, H., Shimuzu, M. and Morita, M. (1997) Effects of triphenyltin chloride and five other organotin compounds on the development of imposex in the rock shell. Environ. Pollut., 95, 85-91.

10) Spooner, N., Gibbs, P. E., Bryan, G. W. and Goad, L. J. (1991) The effect of tributyltin upon steroid titres in the female dogwhelk, Nucella lapillus, and the development of imposex. Marine Environ. Res., 32, 37-49.

11) Bettin, C., Oehlmann, J. and Stroben, E. (1996) TBTinduced imposex in marine neogastropods is mediated by a increasing androgen level. Helgol. Meeresunters, 50, 299-317.

12) Bryan, G. W., Bright, D. A., Hummerstone, L. G. and Burt, G. R. (1993) Uptake, tissue distribution and metabolism of ${ }^{14} \mathrm{C}$-labelled tributyltin (TBT) in the dog-whelk. J. Marine Assoc., 73, 889-912.

13) Shiraishi, F., Shiraishi, H., Nishikawa, J., Soya, Y., Sano, T., Kaya, K., Nishihara, T. and Morita, M. (2001) Development of the antagonist assay system for estrogen receptor using yeast and its application to organotin compounds. J. Environ. Chem., 111, 6573.

14) Nemoto, S., Takatsuki, S., Sasaki, K. and Toyoda, M. (2000) Determination of nonylphenol in fish on the market. J. Food Hyg. Soc. Jpn., 41, 377-380.

15) Kawamura, Y., Maehara, T., Wakui, C. and Yamada, T. (2000) Migration of plasticizers and nonylphenol from polyvinyl chloride gloves. J. Food Hyg. Soc. Jpn., 41, 330-334.

16) Jobling, S., Sheahan, D., Osborne, J. A., Matthiessen, P. and Sumpter, J. P. (1996) Inhibition of testicular growth in rainbow trout (Oncophynchus mykiss) exposed to estrogenic alkylphenolic chemicals. Environ. Toxicol. Chem., 15, 194-202.

17) Harries, J. E., Sheahan, D. A., Jobling, S., Matthiessen, P. and Neall, P. (1997) Estrogenic activity in five United Kingdom rivers detected by measurement of vitellogenesis in caged male trout. Environ. Toxicol. Chem., 16, 534-542.

18) Soto, A. M., Justicia, H., Wray, J. W. and Sonnenschein, C. (1991) p-Nonyl-phenol: an estrogenic xenobiotic released from "modified" polystyrene. Environ. Health Perspect., 92, 167173.

19) Nagel, S. C., Saal, F. S. S., Thayer, K. A., Dhar, M. G., Boechler, M. and Welshons, W. V. (1997) Relative binding affinity-serum modified access (RBA-SMA) assay predicts the relative in vivo bioactivity of the xenoestrogen bisphenol A and octylphenol. Environ. Health Perspect., 105, 70-76.

20) Harris, C. A., Henttu, P., Parker, M. G. and Sumpter, J. P. (1997) The estrogenic activity of phthalate esters in vitro. Environ. Health Perspect.,105, 802-811.

21) Sharman, M., Read, W. A., Castle, L. and Gilbert, J. (1994) Levels of di-(2-ethyl-hexyl) phthalate and 
total phthalate esters in milk, cream, butter and cheese. Food Addit. Contam., 11, 375-385.

22) Jobling, S., Reynolds, T., White, R., Parker, M. G. and Sumpter, J. P. (1995) A variety of environmentally persistent chemicals, including some phthalate plasticizers, are weakly estrogenic. Environ. Health Perspect., 103, 582-587.

23) Sonnenschein, C., Soto, A. M., Fernandez, M. F., Olea, N., Serrano, F. O. and Ruiz-Lopez, M. D. (1995) Development of a marker of estrogenic exposure in human serum. Clin. Chem., 41, 18881895.

24) Soto, A. M., Sonnenschein, C., Chung, K. L., Fernandez, M. F., Olea, N. and Serrano, F. O. (1995) The E-screen assay as a tool to identify estrogens: an update on estrogenic environmental pollutants. Environ. Health Perspect., 103, (suppl.) 7, 113-122.

25) Nakai, M., Tabira, Y., Asai, D., Yakabe, Y., Shimyozu, T., Noguchi, M., Takatsuki, M. and Shimohigashi, Y. (1999) Binding characteristics of dialkyl phthalates for the estrogen receptor. Biochem. Biophys. Res. Commum., 254, 311-314.

26) Sharpe, R. M., Fisher, J. S., Millar, M. M., Jobling, S. and Sumpter, J. P. (1995) Gestational and lactational exposure of rats to xenoestrogens results in reduced testicular size and sperm production. Environ. Health Perspect., 103, 1136-1143.

27) Tarkpea, M., Hagen, I., Carlberg, G. E., Kolsaker, P. and Storflor, H. (1985) Mutagenicity, acute toxicity, and bioaccumulation potential of six chlorinated styrenes. Bull. Environ. Contam. Toxicol., 35, 525-530.

28) Chu, I., Secours, V. E., Valli, V. E., Leeson, S. and Shen, S. Y. (1986) Long-term toxicity of octachlorostyrene in the rat. Fundam. Appl. Toxicol., 6, 69-77.

29) Lunde, G. and Bjørseth, A. (1977) Human blood samples as indicators of occupational exposure to persistent chlorinated hydrocarbons. Sci. Total Environ., 8, 241-246.

30) Selden, A. I., Nygren, Y., Westberg, H. B. and Bodin, L. S. (1997) Hexachlorobenzene and octachlorostyrene in plasma of aluminium foundry workers using hexachloroethane for degassing. Occup. Environ. Med., 54, 613-618.

31) Vaz, A. N., Coon, M. J., Peegel, H. and Menon, K. M. J. (1992) Substituted pyridines: Nonsteroidal inhibitors of human placental aromatase cytochrome P-450. Drug Metab. Dispos., 20, 108-112.

32) Nakagawa, Y., Suzuki, T. and Tayama, S. (2000) Metabolism and toxicity of benzophenone in isolated rat hepatocytes and estrogenic activity of its metabolites in MCF-7 cells. Toxicology, 156, 2736.

33) Imaoka, S. and Funae, Y. (1991) Induction of cytochrome $\mathrm{P} 450$ isozymes in rat liver by methyl $\mathrm{n}$ alkyl ketones and $n$-alkylbenzenes. Effects of hydrophobicity of inducers on inducibility of cytochrome P450. Biochem. Pharmacol., 42, (suppl.), s143-s150.

34) Kawamura, Y., Sugimoto, N., Takeda, Y. and Yamada, T. (1998) Identification of unknown substances in food contact polystyrene. J. Food Hyg. Soc. Jpn., 39, 110-119.

35) Kawamura, Y., Kawamura, M., Takeda, Y. and Yamada, T. (1998) Determination of styrene dimers and trimers in food contact polystyrene. J. Food Hyg. Soc. Jpn., 39, 199-205.

36) Kawamura, Y., Nishi, K., Sasaki, H. and Yamada, T. (1998) Determination method of styrene dimers and trimers in instant noodles contained in polystyrene cups. J. Food Hyg. Soc. Jpn., 39, 310-314.

37) Sakamoto, H., Matsuzaka, A., Itoh, R. and Tohyama, Y. (2000) Quantitative analysis of styrene dimer and trimers migrated from disposable lunch boxes. $J$. Food Hyg. Soc. Jpn., 41, 200-205. 